\title{
Semispinalis Cervicis
}

National Cancer Institute

\section{Source}

National Cancer Institute. Semispinalis Cervicis. NCI Thesaurus. Code C52991.

One of the transversospinales group of muscles that arises from the spinous processes

of the second to fifth cervical vertebrae and inserts into the posterior surfaces of the upper five or six thoracic transverse processes; it functions to extend the vertebrae from which it arises. 